THE INTERNATIONAL

REVIEW OF RESEARCH IN

OPEN AND DISTANCE LEARNING

\title{
Educational Leadership for E-Learning in the Healthcare Workplace
}

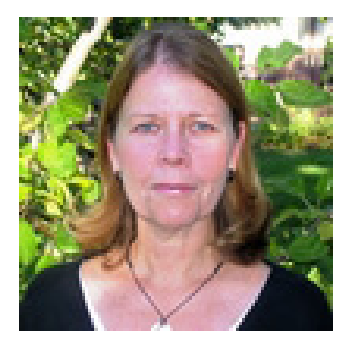

Dorothy (Willy) Fahlman Athabasca University, Canada

\section{Abstract}

Effective educational leadership can make a difference in the resolution of complex issues that impact today's demand-driven educational marketplace. The ongoing professional and skill development needs of human health resources may be best managed through distributed strategic leadership blended with servant leadership. Together these two approaches may offer the critical bridge for effective educational leadership for e-learning within the healthcare workplace.

Keywords: Distributed leadership; strategic leadership; servant leadership; e-learning; healthcare workplace

\section{Introduction}

The context of North American education is changing. In educational organizations, change imposed by technology, economics, global connections, and social awareness is challenging leaders (Cleveland-Innes \& Sangra, 2010). These challenges are not confined to higher educational organizations but also impact societal institutions including the healthcare workplace. The quality and delivery of Canadian healthcare is dependent upon well-trained healthcare providers responding to consumer needs (El-Jardali \& Fooks, 2005). From the perspective of the healthcare workplace, this article explores a distributed strategic leadership approach blended with servant leadership for e-learning. 


\section{Central Issues in Educational Leadership in North America}

In the past three decades, North American society has undergone revolutionary changes due to demographic, economic, technological, and sociocultural issues that are causing the shift from a "supply-driven" to a "demand-driven" educational marketplace (Keller, 2008). Declining birth rates and increasing longevity are shifting the age distribution towards older age groups who are seeking continuing and higher education, coupled with the upward trend for younger adults to be highly educated (Keller, 2008). Increasing immigration requires a greater emphasis on multiculturalism in education to reduce language barriers and increase skill levels (Canadian Council on Learning, 2007). Additionally, the metamorphosis of family life including single parent homes and women working outside the home are creating new demands for education (Keller, 2008). These demographic changes necessitate leadership and innovative pedagogical practices to respond to the diversity of learners' needs.

The shift from domestic capitalism to a more global knowledge economy has resulted in the emphasis on human capital for increased talent and expertise. This move is creating competition in the educational sector (Latchem \& Hanna, 2001). Leadership is required to determine how the education system can effectively contribute to the knowledge-based economy and how each institution within this system evolves (Salmi, 2001).

Technologies are opening access to education across institutional, sectoral, and international boundaries (Latchem \& Hanna, 2001). Without educational leadership that ensures "adequate resources, pedagogy, and educational practices, technology could be an obstacle or burden to genuine learning and will probably increase rather than overcome existing divisions of power, cultural capital, and wealth" (Kellner, 2004, p.12).

The last few decades have seen the move to a more egalitarian society including equal opportunity for education. This openness to equality requires leadership for managing changes in educational structural design, infrastructure and services, content and instructional practices, and pedagogy (Keller, 2008).

\section{Canadian Healthcare Workplace}

The societal changes driven by demographics, economics, technology, and sociocultural issues have also impacted Canadian health human resources (HHR). HHR include regulated and unregulated workers, unionized and nonunionized, and those working in publicly and privately funded delivery models that provide Canadian healthcare services (El-Jardali \& Fooks, 2005).

In 2006, Canada's healthcare workforce was just over 1 million people, or over $6 \%$ of the total Canadian workforce, with the average age of HHR at 41.9 years (CIHI, 2007). The exodus of HHR due to retirement is projected to be critical by 2016 (Spinks \& Moore, 2006).

Changes in gender, cultural, and generational diversity are increasing in the healthcare 
workplace. Approximately $80 \%$ of HHR are female although gender diversification is escalating (CIHI, 2007). Younger workers who are technologically more inclined are noted to place greater value on work-life balance than older cohorts who are more work-centric or preparing for retirement (Spinks \& Moore, 2006).

The years of cost-cutting, downsizing, and restructuring of HHR have caused demoralization and overwork impacting work-life balance and organizational performance (Lowe, 2002). On the agendas of healthcare employers are workplace practices that improve HHR recruitment and retention, health and well-being, quality of patient care and safety, organizational performance, and societal outcomes (Shamian \& El-Jardali, 2007). Part of what Canadians value most in a job is "respect, interesting work, good communication, a sense of accomplishment, work-life balance and opportunities for skill development" (Lowe, 2002, p. 50).

In the healthcare workplace, it is the opportunities for ongoing skill and professional development (PD) that call for educational leadership for e-learning.

\section{Review of the Literature}

Over the past decades, numerous educational leadership theories have gained popularity. However, there is no one specific leadership theory that is universally suitable or ensures infallible leadership performance in the ever-changing educational context (Beaudoin, 2003).

The trait-based theory identifies the key characteristics for successful leaders including physical attributes, intelligence, skill, and personality factors (Bolden, Gosling, Marturano, \& Dennison, 2003). These authors argue that some common traits are found in leaders but no consistent traits can be identified.

Emergent leadership proposes that a group member surfaces to be perceived as the leader. This leader has to be an innovator and at the same time be a conformist to the group's social norms (Curtin, 2004). Curtin posits that leadership which conforms to followers' social norms may be based on self-interest rather than innovation and new direction-seeking.

The leader-member exchange theory (LMX) suggests that leaders develop different follower exchange relationships that impact the leader and member outcomes (Avolio, Walumbwa, \& Weber, 2009). Dyadic relationships may create followers' "in-groups" versus "out-groups" that result in inequities and distrust (Horner, 1997).

Contingency leadership suggests that maximization of followers' performance is dependent upon the interaction of the situation, people, task, organisation, and other environmental variables (Bolden et al., 2003). However, if everything is an interaction that turns into a contingency then "it may become difficult to do what science needs to do-which is to provide a model that, in some way, reduces a phenomenon" (Sternberg, 2005, p.198). Subsequently, the contingency approach may be more appropriate for supervising small groups 
of followers rather than leading educational organizations into the future (Aronson, 2001).

Transactional leadership is built on contingent reinforcement where followers are motivated by positive or negative feedback (Bass \& Steidlmeier, 1999). Using control strategies maintains the status quo within an organization (Aronson, 2001). The current educational marketplace calls for leaders to embrace change and innovation with new organizational structures and pedagogical models rather than controlling and maintaining the status quo.

Transformational leadership is intrinsic and value-driven, creating a collaborative vision for empowering stakeholders to work together to achieve a shared goal (Burns, 1978). Critics argue that there can be pseudotransformational leaders whose behavior may be deceptive and devious; authentic transformational leaders operate out of genuine concern for others and foster an organizational culture with high ethical standards (Bass \& Steidlmeier, 1999).

Strategic leaders' attributes and skills are adapted from transformational and transactional leadership theories. In times of change, organizational learning processes benefit from transformational leadership, while during stable times the transactional approach may reinforce current organizational learning (Vera \& Crossan, 2004). Historically, strategic leadership has centered on an individual leader at the top of the hierarchical pyramid. This model is becoming increasingly counterproductive and "strategic leaders constrained by their abilities to deal with rapidly increasing amounts of data and the general complexity of the global economy ... a are now challenged to discharge their strategic leadership responsibilities differently" (Ireland \& Hitt, 2005, p. 66).

Distributed leadership focuses on leadership practice that is widely shared between leaders. It is characterised by interdependence and cooperation that encourages members to contribute their knowledge and expertise in the leadership activity (Harris, 2004). Distributed leadership works only in teams where members recognize the potential for leadership practice to coexist as a function rather than a position (Thornton, 2010). As Thornton indicates, distributed leadership focuses on maximizing the capacity of people within organizations by concentrating on expertise wherever it exists.

In servant leadership, the focus is on the role of the leader as a servant rather than on selfinterest (Stone, Russell, \& Patterson, 2003). Sendjaya, Sarros, and Santora (2008) argue servant leaders encourage followers' learning, growth, and autonomy for development of future leaders in learning organizations. However, caution must be exercised that the followers' needs do not take precedence over organizational objectives.

Research on leadership styles and outcomes for managing the challenging healthcare workplace has examined how leaders can increase satisfaction, recruitment, and retention and promote healthy work environments (Cummings et al., 2010). Gilmartin and D'Aunno's (2007) review of empirical studies of leadership in the healthcare workplace for the period of 1989-2005 concluded that participative and person-focused leadership styles are linked to reduced HHR work stress, increased group cohesion, empowerment, and self-effi- 
cacy associated with job satisfaction and retention. Additionally, Cummings et al.'s (2010) systematic literature review from 1985-2009 on leadership styles in nursing identified that relationship or people-focused leadership practices were empirically linked to improved outcomes in this context.

\section{E-learning and Educational Leadership in the Healthcare Workplace}

To respond to the multifaceted challenges in the healthcare workplace, educational leadership is required for creating a culture that seeks opportunity for new directions. In the interests of recruitment and retention of HHR in the Canadian healthcare workplace, education for ongoing skills and PD should be broadened and be more inclusive (Shamian \& El-Jardali, 2007). The Canadian Council on Learning (2007) also states that employers who support workplace training and skills development receive a significant return on their investment impacting positively on productivity, innovation, and economic success. E-learning in various delivery formats is noted to be an excellent medium for promoting knowledge and skill development in HHR (Chambers, Conklin, Dalziel, \& MacDonald, 2008; MacDonald, Stodel, Hall, \& Weaver, 2009).

\section{E-learning in the Healthcare Workplace}

Historically, education and training programs in the healthcare workplace have been delivered in a face-to-face format. Attendance at these programs has become increasing difficult due to budget and time constraints, staffing shortages, lack of employer or administrative support, scheduling difficulties, and family responsibilities (Penz et al., 2007). "Addressing these 'new age' challenges requires 'new age' approaches and tools to support the teaching and learning of health care professionals” (Kenny, Park, Van Neste-Kenny, Burton, \& Meiers, 2009, p. 79).

In the healthcare workplace, e-learning can promote reflection and higher level thinking for knowledge exchange, synthesis, application, and translation for improving healthcare (MacDonald, Archibald, Stodel, Chambers, \& Hall, 2008). E-learning includes either synchronous or asynchronous formal learning modes such as online courses or conferencing, and informal learning. Formal e-learning incorporates objectives and outcomes defined by an instructor or educational institution, while informal e-learning is implicit, unintended, opportunistic, and unstructured learning undertaken on the learner's own terms without either prescribed curricular requirements or a designated instructor (Eraut, 2004; Livingstone, 2001). Informal e-learning that impacts skill and PD could be situated at the pointof-care using mobile devices, enabling HHR to interact, maximize ideas, and expand the boundaries for just-in-time learning (McGreal, 2005).

By providing HHR with the opportunity for skills and PD using e-learning, the quality of work-life and overall performance of the healthcare system may be enhanced well into the future (Lowe, 2002). It is up to educational leaders to leverage this strength. 


\section{Educational Leadership for E-learning}

In this climate of growing societal demands, technology, and the complexities of the global economy, it is becoming increasingly difficult for single individuals at the top of a workplace pyramid to have all the answers (Ireland \& Hitt, 2005). In the healthcare workplace, strategic distributive leadership at the senior administrative level blended with servant leadership at departmental levels might be the critical bridge for effectively engaging HHR in e-learning.

With senior administrative leaders, holistic forms of distributed strategic leadership that include intellectual, emotional, spiritual, and behavioral dimensions may produce high levels of interdependence among the leaders emerging from multidirectional and dynamic social processes (Gill, 2006). Hence, the heterogeneity of knowledge and skills would focus on leaders strategically interacting for collaborative and strategic decision-making towards the vision of e-learning in the healthcare workplace. These leaders use a transformational approach to develop a collective healthcare workplace vision for e-learning that springboards off the urgency for HHR recruitment and retention. Instead of providing the answers, distributed strategic leaders will strive to ask the right questions that empower stakeholders to work collaboratively, build engagement, capability, and alignment (Ireland \& Hitt, 2005). This approach requires validation of HHR concerns, open communication, empathy, and active listening to seek different perspectives that inspire engagement in elearning (Gill, 2006).

Where leadership is wholly top-down and outside the departments, employees will be slow to embrace change; it is important to build leadership capacity at all departmental levels (Latchem \& Hanna, 2002). In the healthcare workplace, a blending of distributed strategic leadership with servant leadership has the potential to support and inform pedagogical practice with e-learning. Both servant leadership and the transformational aspect of strategic leadership "emphasize the importance of appreciating and valuing people, listening, mentoring or teaching, and empowering followers” (Stone et al., 2003, p.3).

At the department level, servant leaders are called to lead rather than driven to lead; the servant leaders' focus is on other people rather than self-interest (Stone et al., 2003). Servant leadership promotes teamwork and community involvement in decision-making based on ethical and caring behavior that enhances the growth of people and quality of institutions (Swearingen \& Liberman, 2004). Servant leadership is characterized by "service orientation, holistic outlook, and moral-spiritual emphasis" (Sendjaya et al., 2008, p. 402) that promotes equality and shared values, respect, open-ended commitment, mutual trust, interconnectedness, and concern for others. As Senge (1997) states "learning organizations are built by servant leaders" (p. 17).

\section{Significance of Educational Leadership for E-Learning in the Healthcare Workplace}

The blending of distributed strategic leadership with servant leadership can set direction and develop shared strategies to achieve a vision for effective e-learning for HHR using the 
following:

- awareness that helps educational leaders to understand issues involving ethics, power, and values from a more integrated and holistic approach with e-learning;

- foresight to discern possible consequences for the future and to learn from past lessons with HHR to prevent problems with e-learning; and

- conceptualization to look towards long-term goals while strategically balancing day-today operations (Swearingen \& Liberman, 2004).

For the healthcare workplace to evolve as a learning organization, these leaders must employ e-learning and thus provide HHR with opportunities to learn and grow and to respond to their changing work environments. This blended leadership approach has the potential to build and rebuild community spirit and promote a community of practice that engages e-learning for skill and professional development (Swearingen \& Liberman, 2004).

\section{Conclusion}

In the healthcare workplace, there is a call for educational leadership for e-learning that broadens "the vision of what can be accomplished, provides guidance through uncharted waters, gains commitment and creates systems that are responsive, energizing and sustainable" (Latchem \& Hanna, 2002, p. 213). It is a call for leadership that transforms and increases a shared vision and value focus, creativity and innovation, responsiveness and flexibility, commitment to service, which includes respect, and diversity (Hamilton, 2008). To answer this call, leadership is needed for informing pedagogical practices in the healthcare workplace that is outside the traditional hierarchy, which focuses on one leader. Instead, a distributed strategic and servant leadership blend is required that generates teamwork and community building, shared decision making, and ethical and caring behavior that encourages interdependence and interaction among HHR to serve as well as lead (Neill \& Saunders, 2008). Moreover, blended leadership may provide the critical bridge for incorporating effective e-learning to advance the skills and PD of HHR to meet Canadian healthcare needs in the $21^{\text {st }}$ century. 


\section{References}

Aronson, E. (2001). Integrating leadership styles and ethical perspectives. Canadian Journal of Administrative Science, 18(4), 244-256.

Avolio, B.J., Walumbwa, F.O., \& Weber, T. J. (2009). Leadership: Current theories, research, and future directions. Annual Review of Psychology, 6o, 421-449.

Bass, B. M., \& Steidlmeier, P. (1999). Ethics, character, and authentic transformational leadership. The Leadership Quarterly, 1O(2), 181 -217.

Beaudoin, M. F. (2003). Distance education leadership: An appraisal of research and practice. In M.G. Moore \& W. G. Anderson (Eds.), Handbook of distance education (pp. 519-530). Mahwah, NJ: Lawrence Erlbaum Associates.

Bolden, R., Gosling, J., Marturano, A., \& Dennison, P. (2003). A review of leadership theory and competency frameworks. Centre for Leadership Studies, University of Exeter.

Burns, J. M. (1978). Leadership. New York: Harper \& Row.

Canadian Council on Learning. (2007). Canada's biggest economic challenge: Improving workplace learning in Canada. Retrieved from http://www.ccl-cca.ca/pdfs/LessonsInLearning/Mar-15-07-Canada\%27s-biggest.pdf

Canadian Institute of Health Information (CIHI). (2007). Canada's health care providers, 2007. Ottawa: CIHI. Retrieved from http://secure.cihi.ca/cihiweb/products/ HCProviders o7 EN final.pdf

Chambers, L. W., Conklin, J., Dalziel, W. B., \& MacDonald, C. J. (2008). E-learning education to promote interprofessional education with physicians, pharmacists, nurses and nurse practitioners in (LTC) facilities: Promising potential solutions. International Journal of Biomedical Engineering and Technology, 1(3), 233-249.

Cleveland-Innes, M., \& Sangra, A. (2010). Leadership in a new era of higher distance education. In M. Cleveland-Innes \& D.R. Garrison (Eds.) Introduction to distance learning: Understanding teaching and learning in a new era. New York: Routledge Publishing Inc.

Cummings, G. G., MacGregor, T., Davey, M., Lee, H., Wong, C. A., Lo, E., Muise, M., et al. (2010). Leadership styles and outcome patterns for the nursing workforce and work environment: A systematic review. International Journal of Nursing Studies, $47(3), 363-385$.

Curtin, J. L. (2004). Emergent leadership: Case study of a jury foreperson. Leadership Review, $4,75-88$.

El-Jardali, F., \& C. Fooks. (2005). An environmental scan of current views on health hu- 
man resources in Canada: Identified problems, proposed solutions and gap analysis. Toronto: Health Council of Canada.

Eraut, M. (2004). Informal learning in the workplace. Studies in Continuing Education, $26(2), 247-273$.

Gill, R. (2006). Redefining leadership: A new model. In Theory and practice of leadership (pp.63-95). London: SAGE Publications

Gilmartin, M. J., \& D'Aunno, A. (2007). Leadership research in healthcare. The Academy of Management Annals, 1, 387-438. doi:10.1080/078559813

Hamilton, F. (2008). Servant leadership. In A. Marturano \& J. Gosling, (Eds.), Leadership: The key concepts. (pp. 146-50). London: Routledge.

Harris, A. (2004). Distributed leadership and school improvement. Educational Management Administration \& Leadership, 32(1), 11-24. doi: 10.1177/1741143204039297

Horner, M. (1997). Leadership theory: past, present and future. Team Performance Management, 3(4), 270- 287.

Ireland, R.D. \& Hitt, M. A. (2005). Achieving and maintaining strategic competitiveness in the 21st century: The role of strategic leadership. Academy of Management Executive, 19(4), 63-77.

Keller, G. (2008). Higher education and the new society. Baltimore: John Hopkins University Press

Kellner, D. (2004). Technological transformation, multiple literacies, and the re-visioning of education. E-Learning, 1(1), 9-37.

Kenny, R. F., Park, C., Van Neste-Kenny, J. M., Burton, P., \& Meiers, J. (2009). Using mobile learning to enhance the quality of nursing. In M. Ally (Ed.), Mobile learning transforming the delivery of education and training (pp 75-98). Edmonton: AU Press.

Latchem, C., \& Hanna, D.E. (2001). (Eds.). Leadership for $21^{\text {st }}$ century learning: Global perspectives from educational innovators. London: Routledge.

Latchem, C., \& Hanna, D.E. (2002). Leadership for open and flexible learning. Open Learning: The Journal of Open and Distance Learning, 17(3), 203-215.

Livingstone, D. (2001). Adults' informal learning: Definitions, findings, gaps and future research. Toronto: Centre for the Study of Education and Work, OISE/UT. Retrieved from https://tspace.library.utoronto.ca/bitstream/1807/2735/2/21adultsi nformallearning.pdf 
Lowe, G.S. (2002) High-quality healthcare workplaces: A vision and action plan. Hospital Quarterly, 5(4), 49-56.

MacDonald, C.J., Archibald, D., Stodel, E., Chambers, L.W., \& Hall, P. (2008). Knowledge translation of interprofessional collaborative patient-centred practice: The working together project experience. McGill Journal of Education, 43(3), 283-307.

MacDonald, C. J., Stodel, E. J., Hall, P., \& Weaver, L. (2009). The impact of an online learning resource designed to enhance interprofessional collaborative practice in palliative care: Findings from the caring together pilot project. Journal of Research in Interprofessional Practice and Education, 1(1), 42-66.

McGreal, R. (2005). Mobile devices and the future of free education. Paper presented at the ICDE World Conference 2005, October 24-28. New Delhi: International Council for Distance Education.

Neill, N.W., \& Saunders, M.S. (2008). Servant leadership enhancing quality of careand staff satisfaction. The Journal of Nursing Administration, 38(9), 395-400.

Penz, K., D’Arcy, C., Stewart, N., Kosteniuk, J., Morgan, D., \& Smith, B. (2007). Barriers to participation in continuing education activities among rural and remote nurses. The Journal of Continuing Education in Nursing, 38(3), 58-66.

Sendjaya, S., Sarros, J.C., \& Santora, J.C. (2008). Defining and measuring servant leadership behaviour in organizations. Journal of Management Studies, 45(2), 402-424.

Salmi, J. (2001). Tertiary education in the twenty-first century challenges and opportunities. Higher Education Management, 13(2), 105-130.

Senge, P. M. (1997). Creating learning communities. Executive Excellence, 14(3), 17-18.

Shamian, J., \& El-Jardali, F. (2007). Healthy workplaces for health workers in Canada: Knowledge transfer and uptake in policy and practice. Healthcare Papers, 7, 6-25.

Spinks, N., \& Moore, C. (2006). The changing workforce, workplace and nature of work: Implications for health human resource management. Nursing Leadership, 2O(3), 26-41.

Sternberg, R. J. (2005). WICS: A model of positive educational leadership comprising wisdom, intelligence, and creativity synthesized. Educational Psychology Review, 17(3), $191-262$.

Stone, A.G., Russell, R. F., \& Patterson, K. (2003). Transformational versus servant leadership: A difference in leader focus. Leadership \& Organization Development Journal, 25(4), 349-361.

Swearingen, S., \& Liberman, A. (2004). Nursing leadership: Serving those who serve oth- 
ers. The Health Care Manager, 23(2), 100-109.

Thornton, K. (2010). The nature of distributed leadership and its development in online environments. Retrieved from http://64.225.152.8/downloads/excerpts/34599. pdf

Vera, D., \& Crossan, M. (2004). Strategic leadership and organizational learning. Academy of Management Review, 29(2), 222-240.

\section{Athabasca University $\mathbf{I}$}

(c) 